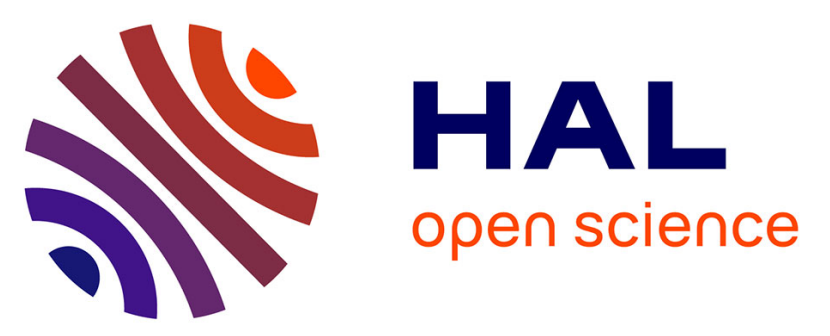

\title{
Experimental validation of a Monte Carlo model to predict EPID images for online verification in radiotherapy
}

Delphine Lazaro-Ponthus, Juan-Carlos Garcia-Hernandez, T. Lamotte, Samuel Legoupil

\section{To cite this version:}

Delphine Lazaro-Ponthus, Juan-Carlos Garcia-Hernandez, T. Lamotte, Samuel Legoupil. Experimental validation of a Monte Carlo model to predict EPID images for online verification in radiotherapy. 2009 IEEE Nuclear Science Symposium and Medical Imaging Conference (NSS/MIC 2009), Oct 2009, Orlando, United States. pp.3296-3299, 10.1109/NSSMIC.2009.5401734 . cea-02545863

\section{HAL Id: cea-02545863 https://hal-cea.archives-ouvertes.fr/cea-02545863}

Submitted on 30 Apr 2020

HAL is a multi-disciplinary open access archive for the deposit and dissemination of scientific research documents, whether they are published or not. The documents may come from teaching and research institutions in France or abroad, or from public or private research centers.
L'archive ouverte pluridisciplinaire HAL, est destinée au dépôt et à la diffusion de documents scientifiques de niveau recherche, publiés ou non, émanant des établissements d'enseignement et de recherche français ou étrangers, des laboratoires publics ou privés. 


\title{
Experimental validation of a Monte Carlo model to predict EPID images for online verification in radiotherapy
}

\author{
D. Lazaro-Ponthus ${ }^{1}$, T. Lamotte ${ }^{1}$, J. Garcia-Hernandez ${ }^{1}$ and S. Legoupil ${ }^{1}$ \\ ${ }^{1}$ CEA, LIST, Saclay, F-91191 Gif-sur-Yvette, France
}

\section{INTRODUCTION}

Thanks to recent improvements in external beam radiotherapy, it has become possible to deliver accurately very high doses to the tumor. The increasing complexity of the treatments has driven the need for a thorough verification of the delivered dose, either pretreatment or in vivo. Electronic portal imaging devices (EPIDs), initially introduced for patient positioning, have also demonstrated their great potential for dosimetric verification [1]. To achieve this goal, one proposed strategy is based on the comparison of a predicted dose image with a portal image acquired before and/or during treatment. Monte Carlo (MC) simulations (mainly using the EGSnrc code) were recently shown to predict reliably portal images of conventional and intensity modulated fields [2,3]. The purpose of this study is to investigate the feasibility of using the MC code PENELOPE to predict portal images and to validate a portal prediction model against measurements.

\section{MATERIAL AND METHODS}

\section{A. Experimental set-up}

Measurements were carried out at the LNHB laboratory (CEA-LIST, France) using a Saturne 43 accelerator (GEMS) equipped with a fluoroscopic Lynx2D EPID (FIMEL, France). This EPID consists of a fluorescent screen, made of a $1 \mathrm{~mm}$ thick copper plate coated with a $\mathrm{Gd}_{2} \mathrm{O}_{2} \mathrm{~S}: \mathrm{Tb}$ (GOS) fluorescent layer, viewed by a CCD camera via a mirror tilted at an angle of $45^{\circ}$. The CCD camera contains $600 \times 600$ pixels of $0.5 \times 0.5 \mathrm{~mm}^{2}$ each and has a 10 bit dynamic range. The active area of the EPID at the level of the fluorescent screen is $30 \times 30 \mathrm{~cm}^{2}$.

Open-field portal images were acquired for different field sizes $\left(4 \times 4,10 \times 10\right.$ and $\left.15 \times 15 \mathrm{~cm}^{2}\right)$, both without object in the beam (in-air images) and with a $30 \times 30 \times 30 \mathrm{~cm}^{3}$ water cubic phantom placed so that its entrance surface was located at $90 \mathrm{~cm}$ from the source. The source-to-isocenter distance and the source detector distance (SDD) were set to $100 \mathrm{~cm}$ and $150 \mathrm{~cm}$, respectively. Each acquired image was formed by averaging 15 images of $10 \mathrm{~s}$ each, at a dose rate of $200 \mathrm{MU} / \mathrm{min}(1.7 \mathrm{~Gy} / \mathrm{min})$ with a photon beam energy of $12 \mathrm{MV}$. EPID images were then corrected for the difference in pixel gain and offset values by subtracting a dark-field image and dividing by a flood-field image.

\section{B. Monte Carlo simulations}

\section{1) Modeling of the accelerator treatment head and the EPID}

The PENELOPE MC code [4] was used to model the accelerator treatment head and compute portal images. In a first step, phase space files (PSF) storing information about each particle at the exit of the accelerator head (position, direction and energy) were pre-computed using a previously commissioned model of the accelerator head [5]. One PSF was computed per field size and scored about 150 million particles. Secondly, portal images at the EPID plane were simulated by using the pre-computed PSF as input data. The photon and electron/positron transport cut-offs were set to $0.01 \mathrm{MeV}$ and $0.70 \mathrm{MeV}$ respectively.

Two kinds of EPID models were investigated, differing by the complexity level in the geometry. A detailed geometry was first built following the manufacturer specifications and included every EPID components (fluorescent screen, mirror and shielding). A simplified model was also implemented, in which the fluorescent screen was modeled as two uniform layers of copper and GOS; beneath them was added a uniform water slab to take into account for the photons undergoing backscatter within the EPID structure and on the lab walls. In order to adjust the backscatter compartment thickness, average values were calculated on a $6 \times 6 \mathrm{~cm}^{2}$ central area of measured and computed portal images for $10 \times 10 \mathrm{~cm}^{2}$ and $15 \times 15 \mathrm{~cm}^{2}$ open fields. The ratio $\mathrm{R}$ of the average values between the $10 \times 10 \mathrm{~cm}^{2}$ field and the $15 \times 15 \mathrm{~cm}^{2}$ field was determined on measured images and the backscatter compartment thickness was varied until the same value of $\mathrm{R}$ was found on simulated images [6]. The EPID response was then computed by scoring the energy deposited in the GOS layer, represented by a virtual grid of $150 \times 150$ pixels of $2 \times 2 \mathrm{~mm}^{2}$ each.

\section{2) Simulated configurations}

A first set of simulations was conducted to determine which EPID model performed at best to compute portal images. For that, in-air portal images were simulated at SDD $=150 \mathrm{~cm}$ using a standard $10 \times 10 \mathrm{~cm}^{2}$ open field, for several EPID geometries: (1) the detailed model, (2) the simplified model without backscatter, (3) the simplified model with a $5 \mathrm{~cm}$ backscatter water layer and (4) the simplified model with an $8 \mathrm{~cm}$ backscatter water layer. Once the optimal EPID model determined, portal images were simulated for all open field sizes $(4 \times 4,10 \times 10$ and $15 \times 15$ $\mathrm{cm}^{2}$ ) without object in the beam and with the $30 \times 30 \times 30 \mathrm{~cm}^{2}$ water phantom placed at $90 \mathrm{~cm}$ from the source. For these simulations, the SDD was set to $150 \mathrm{~cm}$ as in the experimental configurations.

\section{Determination and validation of the EPID model}

The determination of the optimal EPID model was done by comparing the measured profile with the profiles drawn on the central axis through simulated images using the four different models described above. Simulated profiles were normalized to the averaged value on the three central points of the measured profile. In order to validate the EPID model for all field sizes and all configurations (in air and with the water phantom in the beam), on-axis profiles drawn through measured and simulated EPID images, as well as measured and simulated images themselves, were then compared to corresponding measured profiles and portal images, respectively. The difference between simulation and measurements was assessed by calculating the gamma index [4] both on profiles and images, using $3 \%$ and $3 \mathrm{~mm}$ as values for the dose-difference and the distanceto-agreement criteria, respectively.

\section{RESULTS AND DISCUSSION}

\section{A. Determination of the optimal EPID model}

The comparison between profiles computed for the four different EPID geometries shown on Fig.1 demonstrates clearly that the presence of a backscatter compartment is mandatory in the model to correctly simulate the EPID signal inside and outside the field. Moreover, the profiles obtained when simulating the whole EPID (detailed geometry) and without backscatter are almost identical and show that the mirror and the shielding do not affect significantly the EPID signal inside and outside the field. This means that the EPID signal is increased either by photons backscattering on the lab walls or by optical photons backscattering within the EPID structure or both. Portal images were computed for a 
backscatter compartment thickness of 5,8 and $10 \mathrm{~cm}$ and values of the ratio $\mathrm{R}$ of $0.918,0.907$ and 0.898 were obtained, respectively. As an R value of 0.906 was determined experimentally, the thickness of the backscatter compartment in the simulation model was finally set to $8 \mathrm{~cm}$ to match the experimental result.

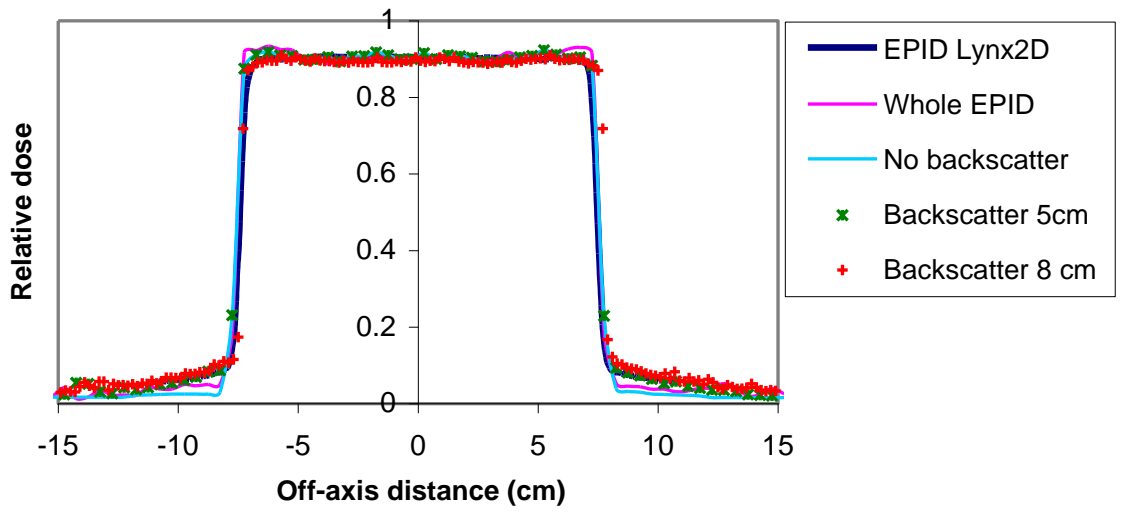

Fig.1. Comparison of the measured profile with simulated profiles for the four tested EPID models, for a 10x10 $\mathrm{cm}^{2}$ field.

\section{B. Validation of the EPID model for in-air and water phantom images}

Simulated and measured profiles drawn for in-air and the water phantom configurations are shown on Fig.2, for the $4 \times 4,10 \times 10$ and $15 \times 5 \mathrm{~cm}^{2}$ open fields, whereas gamma index values for both the profiles (1D) and the images (2D) are presented in Table 1. Gamma analysis between computed and measured profiles reveals a gamma value less than 1 for $98 \%$ of all points. Discrepancies are mostly observed in the steep dose gradient regions and are mainly due to the uncertainty in the positioning of the EPID. For portal images, a gamma value less than 1 for $90 \%$ of the pixels when considering large field sizes and for $96 \%$ of the pixels when considering fields of size $10 \times 10 \mathrm{~cm}^{2}$ or less. Results are a little bit degraded outside the field for large field sizes because measured portal images were not corrected for the cross-talk effect. These results show a good agreement between simulation and experiment and exhibit that the model of the EPID implemented allows computing accurately portal images of open fields, with or without an object in the beam.
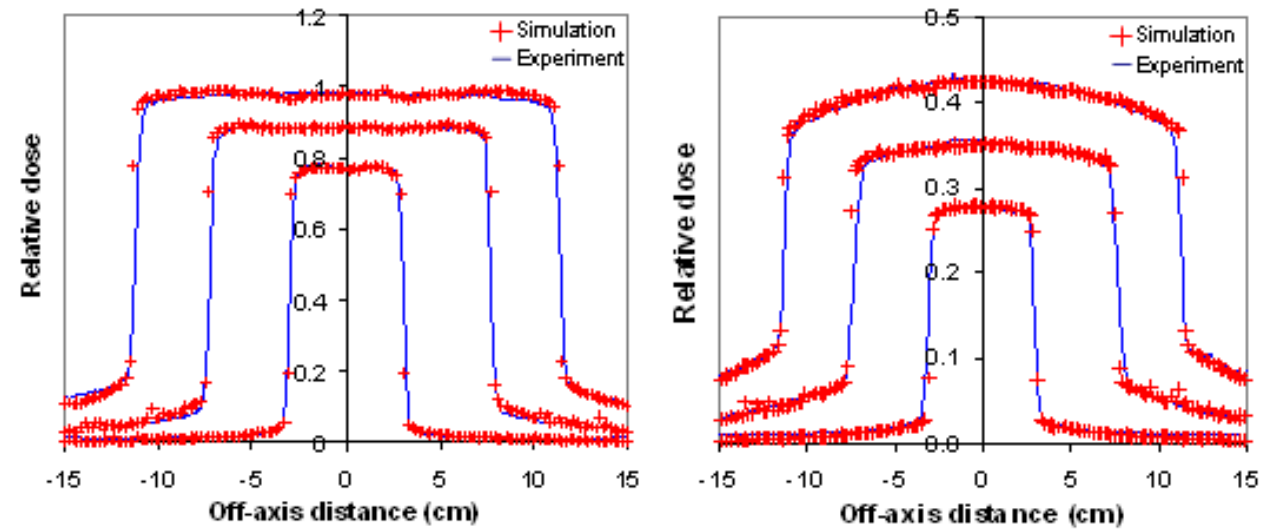

Fig.2. Comparison of measured and simulated profiles drawn through in-air images (left) and images of the water phantom (right).

\begin{tabular}{|c|c|c|c|}
\hline \multirow{2}{*}{$\begin{array}{c}\text { Portal } \\
\text { image }\end{array}$} & \multirow{2}{*}{$\begin{array}{c}\text { Field } \\
\text { size } \\
\left(\mathrm{cm}^{2}\right)\end{array}$} & \multicolumn{2}{|c|}{$\begin{array}{c}\text { Gamma } \\
\text { index }(\%)\end{array}$} \\
\cline { 2 - 4 } & $4 \mathrm{D}$ & $2 \mathrm{D}$ \\
\hline \multirow{3}{*}{ In-air } & $4 \times 4$ & 99.3 & 98.6 \\
\cline { 2 - 4 } & $10 \times 10$ & 98.1 & 96.4 \\
\cline { 2 - 4 } & $15 \times 15$ & 98.3 & 90.2 \\
\hline \multirow{2}{*}{$\begin{array}{c}\text { Water } \\
\text { phantom }\end{array}$} & $4 \times 4$ & 99.6 & 98.7 \\
\cline { 2 - 4 } & $10 \times 10$ & 99.0 & 96.5 \\
\cline { 2 - 4 } & $15 \times 15$ & 99.3 & 91.8 \\
\hline
\end{tabular}

Table 1. Gamma index values computed on $1 \mathrm{D}$ profiles and $2 \mathrm{D}$ images, between measured and simulated configurations.

\section{CONClusion}

This study shows that portal images can be computed accurately by using the MC code PENELOPE. A simple model of the EPID, based on three layers (copper, GOS, water), was validated: it was demonstrated that this model must include a backscatter compartment, whose thickness must be adjusted carefully to take into account the backscattered radiation within the EPID structure and on the lab walls. Using this model, we show that it is possible to predict reliably portal images acquired with a fluoroscopic EPID, in air or with an object in the beam, for open fields. This model can be used to compute MC predicted portal images for pre-treatment or online verification in radiotherapy or to help the development of dose reconstruction methods as a tool to investigate the influence of patient scatter on the EPID image formation.

\section{ACKNOWLEDGMENTS}

We would like to thank people of the LNHB laboratory for their useful help to the experimental part of this work and J. Guillon (FIMEL) to provide us with the description of the Lynx2D EPID. This work was funded by MEDICEN, in the framework of the MINIARA project.

\section{REFERENCES}

[1] van Elmpt W, McDermott L, Nijsten S, Wendling M, Lambin P and Mijnheer 2008 A literature review of electronic portal imaging for radiotherapy dosimetry Radioth. Oncol. 88 289-309

[2] van Elmpt W, Nijsten S, mijnheer B and Minken A 2005 Experimental verification of a portal dose prediction model Med. Phys. 32 2805-18

[3] Spezi E and Lewis DG 2002 Full forward Monte Carlo calculation of portal dose from MLC collimated treatment beam Phys. Med. Biol. 47 377-90

[4] Baro J, Sempau J, Fernandez-Varea JM and Salvat F 1995 PENELOPE: an algorithm for Monte-Carlo simulation of the penetration and energy loss of electrons and positrons in matter Nucl. Instr. and Meth. B 100 31-46

[5] Habib B, Poumarède B, Tola F and Barthe J 2009 Evaluation of PENFAST - A fast Monte Carlo code for dose calculations in photon and electron radiotherapy treatment planning Physica Medica in press

[6] Siebers JV, Kim JO, Ko L and Keall PJ 2004 Monte Carlo computation of dosimetric amorphous silicon electronic portal images Med. Phys. 31 2135-46

[7] Low DA, Harms WB, Mutic S and Purdy JA 1998 A technique for the quantitative evaluation of dose distributions Med. Phys. 25 656-6 